\title{
Neonatal prophylaxis with antibiotic containing ointments does not reduce incidence of chlamydial conjunctivitis in newborns
}

Tamar A. Smith-Norowitz ${ }^{1 *}$, Crystal Ukaegbu ${ }^{1,2}$, Stephan Kohlhoff ${ }^{1}$ and Margaret R. Hammerschlag ${ }^{1}$

\begin{abstract}
Background: Neonatal ocular prophylaxis with silver nitrate does not prevent neonatal conjunctivitis due to Chlamydia trachomatis. The efficacy of antibiotic containing preparations for prevention of neonatal chlamydial conjunctivitis (NCC) has not been established.

Objective: To examine published literature to determine whether antibiotic containing preparation are efficacious for prevention of NCC and C. trachomatis in the nasopharynx.

Methods: A literature search of MEDLINE and EMBASE. Articles were selected for review if their content included 4 key criteria: (1) Prospective/comparative study. (2) Prenatal screening of mothers for C. trachomatis with results reported. (3) Follow-up of infants born to chlamydia-positive women. (4) Infants prospectively followed at regular intervals and tested for C. trachomatis in the eye/ nasopharynx (NP).

Results: The search yielded 159 studies; 11 were selected for full reviews, eight were excluded; three addressed the four criteria. Rates of $C$. trachomatis conjunctivitis in infants in included studies who received silver nitrate was 20$33 \%$; positive NP, 1-28\% and pneumonia, 3-8\%. Rates of C. trachomatis conjunctivitis in neonates who received erythromycin or tetracycline prophylaxis did not differ from silver nitrate; 0-15 and 11\%, respectively, who received erythromycin or tetracycline developed NCC. Similarly, 4-33 and 5\% of infants who received erythromycin or tetracycline, respectively, had positive NP cultures; 0-4\% developed chlamydial pneumonia.
\end{abstract}

Conclusion: Neonatal ocular prophylaxis with erythromycin or tetracycline ophthalmic ointments does not reduce incidence of neonatal chlamydial conjunctivitis or respiratory infection in infants born to mothers with $C$. trachomatis infection compared to silver nitrate.

Keywords: Neonatal chlamydial prophylaxis, Chlamydia trachomatis, Silver nitrate, Erythromycin, Tetracycline

\footnotetext{
* Correspondence: tamar.smith-norowitz@downstate.edu

${ }^{1}$ Department of Pediatrics, State University of New York Downstate Medical

Center, 450 Clarkson Ave., Box 49, Brooklyn, NY 11203, USA

Full list of author information is available at the end of the article
}

\section{$\triangle B M C$}

(c) The Author(s). 2021 Open Access This article is licensed under a Creative Commons Attribution 4.0 International License, which permits use, sharing, adaptation, distribution and reproduction in any medium or format, as long as you give appropriate credit to the original author(s) and the source, provide a link to the Creative Commons licence, and indicate if changes were made. The images or other third party material in this article are included in the article's Creative Commons licence, unless indicated otherwise in a credit line to the material. If material is not included in the article's Creative Commons licence and your intended use is not permitted by statutory regulation or exceeds the permitted use, you will need to obtain permission directly from the copyright holder. To view a copy of this licence, visit http://creativecommons.org/licenses/by/4.0/. The Creative Commons Public Domain Dedication waiver (http://creativecommons.org/publicdomain/zero/1.0/) applies to the data made available in this article, unless otherwise stated in a credit line to the data. 


\section{Introduction}

Credé reported in 1881 that instillation of $2 \%$ silver nitrate drops into the eyes of newborn infants reduced the incidence of gonococcal ophthalmia neonatorum [1]. However, the epidemiology of ophthalmia neonatorum has significantly changed since 1881 . Gonococcal ophthalmia is very uncommon mainly due to prenatal screening for Neisseria gonorrhoeae and treatment of pregnant women $[2,3]$. C. trachomatis was the most common cause of neonatal conjunctivitis in the U.S. before the Centers for Disease Control and Prevention (CDC) recommended routine prenatal screening of pregnant women for C. trachomatis in 1993 [2]. Currently, erythromycin ophthalmic ointment is the only preparation available for neonatal ocular prophylaxis in the U.S. [4]; tetracycline ophthalmic ointment is no longer manufactured, and silver nitrate has not been available in the U.S. for over two decades.

Prenatal screening and treatment of pregnant women for chlamydia has resulted in a decrease in neonatal chlamydial conjunctivitis and pneumonia [4-6]. Prospective studies of vertical transmission of C. trachomatis conducted from the 1970s to 1980 s found that neonatal ocular prophylaxis with silver nitrate did not appear to prevent chlamydial ophthalmia or nasopharyngeal (NP) colonization with $C$. trachomatis or chlamydial pneumonia [7-11]. A study published by Hammerschlag, et al in 1980 suggested that neonatal ocular prophylaxis with erythromycin ointment was effective in prevention of chlamydial conjunctivitis but did not reduce NP infection or pneumonia [12]. However, a subsequent study [3] demonstrated that neonatal ocular prophylaxis with either erythromycin or tetracycline ophthalmic ointment did not significantly reduce the incidence of chlamydial conjunctivitis in infants of mothers with chlamydial infection as compared with silver nitrate [3]. Many hospitals in the US switched to erythromycin ophthalmic ointment after the initial study by Hammerschlag et al [12]. The law in many states also specifically mandates neonatal ocular prophylaxis with erythromycin.

The CDC currently recommends neonatal ocular prophylaxis with erythromycin ophthalmic ointment, primarily for prevention of gonococcal ophthalmia [13]. The World Health Organization (WHO) still recommends neonatal ocular prophylaxis for prevention of both gonococcal and chlamydial ophthalmia [14]. The aim of the current study was to review the published literature on whether antibiotic containing preparations are effective in prevention of neonatal chlamydial conjunctivitis.

\section{Methods}

Search strategy and selection criteria: literature search methods

A review was conducted according to Preferred Reporting Items for Systematic Reviews and Meta-Analysis
(PRISMA) protocol guidelines. The PRISMA Protocols consists of a 17-item checklist that facilitates preparing and reporting a protocol for the systematic review.

\section{Eligibility criteria. (inclusion criteria)}

Studies were eligible for inclusion if they included our four key criteria: (1) prospective study and comparative study, (2) prenatal screening of the mothers for C. trachomatis with results reported, (3) follow-up of infants born to $C$. trachomatis-positive women, and (4) infants were seen at regular intervals, cultured/tested for C. trachomatis in the eye/ nasopharynx (NP) whether or not they were symptomatic, and ointments containing antibiotic applied preventatively.

\section{Information sources and search strategy}

Electronic databases, including MEDLINE and EMBASE were used to identify relevant English language articles. Published literature in a wide range of styles and formats were selected for review, after working with a research librarian to develop our search strategy. There were no restrictions on country of origin, type of hospital, study type, journal type or year published. Articles were selected at each level of review due to their inclusion of content that matched with our four key criteria.

The Initial EMBASE search terms included:

1. chlamydia AND prophylaxis AND infant

2. "Ophthalmic Solutions"[Mesh] OR ("Chlamydia"[Mesh] OR "Chlamydia Infections"[Mesh]) AND (Randomized Controlled Trial [ptyp] AND “infant”[MeSH Terms]) The last search date was performed on July 30, 2019.

Study records.

a. Data management. Prisma Admin (data management tool)

b. Selection process. Three independent researchers selected articles from the initial list of titles and abstracts to conduct a full review (Fig. 1). The full text articles were independently assessed for inclusion eligibility (i.e. eligible for further review).

c. Data Collection process. Results of studies were not combined. Data collection was done independently.

Risk of bias in individual studies The risk of bias was assessed in all studies by three independent review authors. Each reviewer then recorded his or her findings on a separate 'Bias Assessment Form'. The form includes risk of bias, confounding and precision. Overlapping concerns of bias were then selected for final review and 


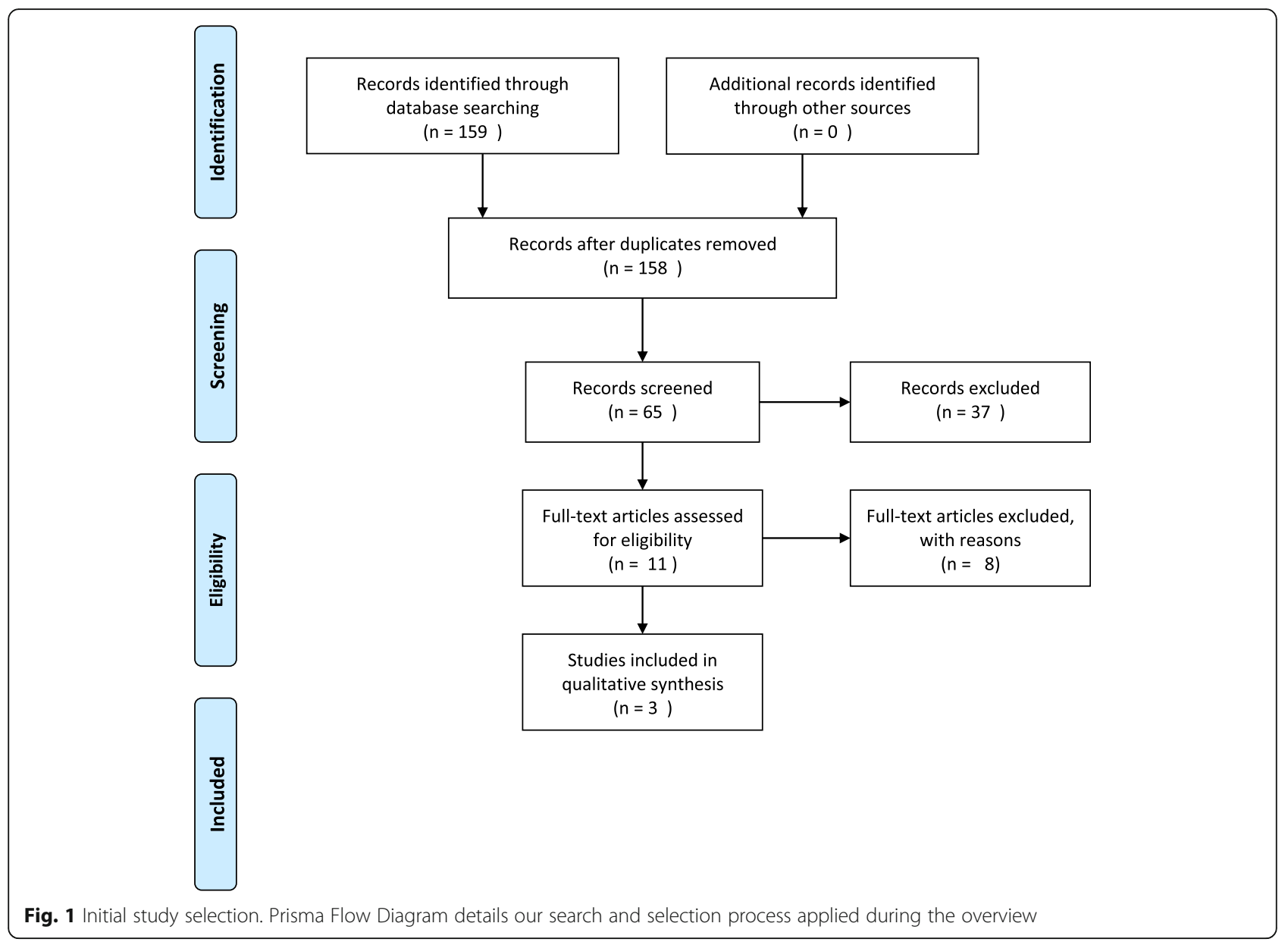

incorporation into the literature review. The concerns wholly addressed bias at the study level. All data were portrayed independently.

\section{Data synthesis and abstract review}

Details of the studies that met the inclusions criteria listed above were then reviewed, summarized, and categorized according to the four key criteria. Three authors independently reviewed each group of abstracts identified by the literature search. A full text article was retrieved in cases in which the reviewers could not determine whether the article met the eligibility criteria from the abstract alone.

\section{Confidence in cumulative evidence Statistical methods}

Exact logistic regression was used to estimate exact odds ratios (ORs) with 95\% confidence intervals (CIs); and to compute exact 2-sided tests of the null hypothesis that $\mathrm{OR}=1$. All statistical analyses were performed at the Scientific Computing Center (SUNY Downstate Medical Center, Brooklyn, NY).

\section{Availability of data and materials}

The data sets supporting the conclusions of this article are included within this article.

\section{Results}

\section{Description and methodology of studies}

The initial search yielded 159 unique published studies; 11 were selected for full-text review, eight were excluded because they did not meet all four key criteria (Fig. 1). Three studies were eligible for inclusion (Fig. 1). Excluded studies are summarized in Table 1, and included studies are summarized in Table 2.

\section{Excluded studies}

Of the eight excluded studies, one was not prospective [22] and seven did not perform prenatal screening for $C$. trachomatis $[15,16,18-22]$. Two of the studies did not follow all the infants prospectively; only infants who returned with conjunctivitis were tested for C. trachomatis [16, 22]. Infants were followed prospectively in four of the studies but were not tested for C. trachomatis in the eye and NP $[16,18,21,22]$. 


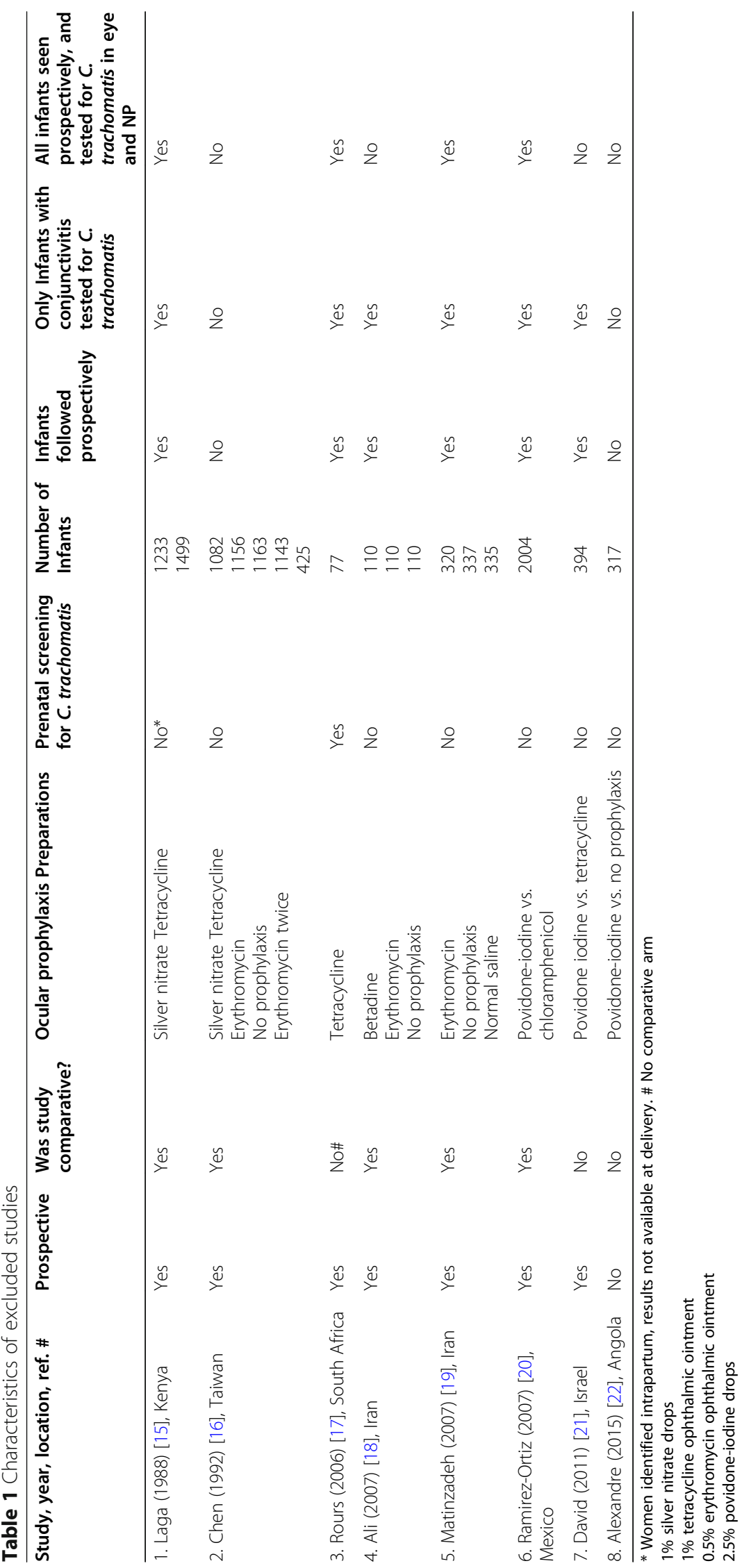


Table 2 Characteristics of included studies

\begin{tabular}{|c|c|c|c|}
\hline & Hammerschlag (1980) [12] & Bell (1987) [23] & Hammerschlag (1989) [3] \\
\hline Location & Seattle, WA & Seattle, WA & Brooklyn, NY \\
\hline Type of Study & Prospective, randomized & Prospective, not randomized & Prospective, randomized \\
\hline Prophylaxis & a. Silver Nitrate, b. Erythromycin & $\begin{array}{l}\text { a. Silver Nitrate, } \\
\text { b. Erythromycin }\end{array}$ & $\begin{array}{l}\text { a. Silver Nitrate, } \\
\text { b. Erythromycin, } \\
\text { c Tetracycline }\end{array}$ \\
\hline Number of Infants & 60 & 120 & 230 \\
\hline Chlamydial Conjunctivitis Number (\%) & $\begin{array}{l}\text { a. } 12(33) \\
\text { b. } 0\end{array}$ & $\begin{array}{l}\text { a. } 21(23) \\
\text { b. } 4(15)\end{array}$ & $\begin{array}{l}\text { a. } 15(20) \\
\text { b. } 13(14) \\
\text { c. } 7(11)\end{array}$ \\
\hline NP Number (\%) & $\begin{array}{l}\text { a. } 10(28) \\
\text { b. } 5\end{array}$ & NR\# & $\begin{array}{l}\text { a. } 1(1) \\
\text { b. } 4(4) \\
\text { c. } 3(5)\end{array}$ \\
\hline Pneumonia Number (\%) & $\begin{array}{l}\text { a. } 3(8) \\
\text { b. } 1 \text { (4) }\end{array}$ & NR & $\begin{array}{l}\text { a. } 2(3) \\
\text { b. } 0 \\
\text { c. } 0\end{array}$ \\
\hline
\end{tabular}

a Silver nitrate; b. Erythromycin; c. Tetracycline

\# Extraocular chlamydial infection without conjunctivitis. Sites tested NP, oropharynx, vagina and anus.

NR Not reported.

Ali, et al, in a study from Iran [18], compared Betadine, erythromycin and no prophylaxis in 330 infants [18]; however, mothers were not tested for $N$. gonorrhoeae or C. trachomatis before delivery [18]. Matinzadeh, et al, also from Iran [19], compared erythromycin to saline in 1002 infants [19]; mothers were also not screened for $N$. gonorrhoeae or C. trachomatis [19]. Ramirez-Ortiz, et al, in a study from Mexico [20], compared $2.5 \%$ povidone-iodine and topical chloramphenicol in 2004 infants [20]; mothers were not screened prenatally. David, et al in a study from Israel of 394 fullterm neonates compared povidone-iodine to tetracycline ophthalmic ointment [21]; pregnant women were not screened for C. trachomatis or N. gonorrhoeae. Laga, et al [15] in a study from Kenya, compared silver nitrate and tetracycline ointment for prophylaxis of ophthalmia in 2732 newborns. Pregnant women were tested for $C$. trachomatis and $N$. gonorrhoeae intrapartum; the results were not available before delivery. Ninety nine percent of infants who received silver nitrate and were exposed to maternal $C$. trachomatis infection were seen in follow-up clinics and $86 \%$ of infants who received tetracycline and were exposed to maternal $C$. trachomatis were seen in follow-up clinics [15].
It should be mentioned that Lund et al studied the incidence of gonococcal ophthalmia neonatorum (GON) in 23, 883 infants in Cape Town [24]; two prophylaxis agents (silver nitrate and erythromycin ophthalmic ointment) were introduced in routine eye care of the newborn [24]. Cases of GON decreased from 28 to 5 over the trial period [24]. However, this study was not used because they did not study Chlamydia ophthalmia [24].

Rours, et al from South Africa [17], followed 77 infants prospectively born to $C$. trachomatis positive mothers. Mothers were screened prenatally for $C$. trachomatis [17], however, there was no comparator, hence this study was not included in the final analysis. All infants received tetracycline ointment for neonatal prophylaxis; C. trachomatis conjunctivitis developed in $39 \%$ of infants born to C. trachomatis positive mothers [17].

\section{Included studies}

The results of the three studies which met the four inclusion criteria are shown in Table 3.

Hammerschlag, et al [12], in a study conducted in Seattle in 1980 ( $N=60$ infants) demonstrated that neonatal ocular prophylaxis with erythromycin ophthalmic ointment decreased incidence of $C$. trachomatis ophthalmia

Table 3 Included studies: Comparison of Efficacy of Neonatal Eye Prophylaxis for Prevention of C. trachomatis conjunctivitis

\begin{tabular}{llll}
\hline Study & Ref. No. & Prophylaxis & Odds ratio, 95\% Cl \\
\hline Hammerschlag (1980) & $\mathbf{1 2}$ & Erythromycin v. Silver nitrate & $0.06[0.00,0.33], p=0.002^{*}$ \\
Bell (1987) & $\mathbf{2 4}$ & Erythromycin v. Silver nitrate & $0.60[0.14,2.04], p=0.436$ \\
Hammerschlag (1989) & $\mathbf{3}$ & Erythromycin v. Silver nitrate & $0.56[0.23,1.38], p=0.206$ \\
& & Tetracycline v. Silver nitrate & $0.44,[0.14,1.25], p=0.104$ \\
\hline
\end{tabular}

* Statistically significant 
neonatorum compared with silver nitrate $(0 \mathrm{v}$. $33 \%$, $\mathrm{OR}=0.06, \mathrm{CI}=[0.00,0.33], p=0.002)$. However, in a subsequent study conducted in Brooklyn in 1989 ( $N=$ 230 infants), Hammerschlag, et al [3] demonstrated that neonatal ocular prophylaxis with erythromycin or tetracycline ophthalmic ointments did not decrease incidence of C. trachomatis ophthalmia neonatorum compared with silver nitrate (erythromycin $14 \%$ : $\mathrm{OR}=0.56, \mathrm{CI}=$ $[0.23,1.38], p=0.206$, tetracycline $11 \%$ : $\mathrm{OR}=0.44, \mathrm{CI}=$ $[0.14,1.25], p=0.104$, v. $20 \%$ for silver nitrate). Bell, et al [23], from Seattle ( $N=120$ infants) demonstrated that neonatal ocular prophylaxis with erythromycin did not decrease the incidence of $C$. trachomatis conjunctivitis compared to silver nitrate $(15 \%$ v. $23 \%, \mathrm{OR}=0.60, \mathrm{CI}=$ $[0.14,2.04], p=0.436)$. Prophylaxis preparations were not randomized, infants received either preparation based on the preferences of the provider and/or parents.

\section{Discussion}

The results of this study suggest that neonatal ocular prophylaxis with erythromycin or tetracycline ophthalmic ointments does not reduce incidence of neonatal chlamydial conjunctivitis or respiratory infection in infants born to mothers with $C$. trachomatis infection compared to silver nitrate. Prenatal screening and treatment of pregnant women is the most effective strategy for prevention of perinatal chlamydial infection, much as prenatal screening and treatment of gonococcal infection has been effective in preventing gonococcal ophthalmia. However, most countries worldwide do not routinely screen pregnant women for C. trachomatis [25].

Silver nitrate was first used for prophylaxis of gonococcal ophthalmia neonatorum in 1881 [1]. However, silver nitrate has not been available in the US for over two decades [4, 26, 27], and side effects include chemical conjunctivitis. The U.S. Preventive Task Force currently recommends neonatal ocular prophylaxis with erythromycin ophthalmic ointment for prevention of gonococcal, not chlamydial, ophthalmia [15]. Several countries in Europe (e.g. United Kingdom, Norway, Sweden, and Denmark) have discontinued universal ocular prophylaxis and others offer parental choice [27]. In 2015, the Canadian Pediatric Society recommended discontinuation of routine neonatal ocular prophylaxis in Canada with an emphasis on enhanced prenatal screening [26]. This policy was implemented in 2016 [8]. Erythromycin ophthalmic ointment has not been available in Canada for several years.

Only three studies met the inclusion criteria as described in the results. The initial 1980 study by Hammerschlag et al [12] yielded a significant result suggesting that ocular prophylaxis with erythromycin was effective in preventing neonatal chlamydial conjunctivitis compared to silver nitrate. However, the sample size was small ( $N=60$ infants). A subsequent larger study ( $N=230$ infants) conducted in Brooklyn, failed to confirm the initial results [3]. Even though the first study of Hammerschlag et al [12] was small, it yielded a highly significant result that induces replication; later larger studies of Hammerschlag et al [3] and Bell et al [23] failed to reproduce the early dramatic result. Sample size is often cited as the reason for why this occurs, and thus, one reason why systematic review is so important. Although Rours et al [17], was excluded from the final analysis because it was not comparative, the proportion of infants born to chlamydia positive mothers who received ocular prophylaxis with tetracycline ointment $(39 \%)$ was similar to that reported in the comparative studies for erythromycin and tetracycline.

Erythromycin ophthalmic ointment is currently the only available FDA approved preparation in the U.S. for ophthalmia neonatorum. There is only one manufacturer and there have been interruptions in the supply. In 2009, the CDC informed physicians of a shortage of $0.5 \%$ erythromycin ointment due to change in manufacturers, and a set of interim guidelines were provided to clinicians of alternative agents (i.e. azithromycin or gentamicin ophthalmic preparations) [28]. However, no data on alternatives available for this indication and use of gentamicin ophthalmic ointment was associated with severe ocular reactions in the infants $[28,29]$.

We are aware of potential limitations of this study. This may include limitations at the study and outcome level (e.g. risk of bias) and/or at the review level (e.g. reporting bias and incomplete retrieval of identified research).

\section{Conclusion}

This review highlights that the evidence of antibiotic prophylaxis for prevention of neonatal chlamydial conjunctivitis is sparse. However, screening and treatment of pregnant women is more effective than neonatal prophylaxis [30, 31].

\section{Abbreviations \\ NCC: Neonatal chlamydial conjunctivitis; GON: Gonococcal ophthalmia neonatorum}

\section{Acknowledgements \\ None.}

Authors' contributions

TSN: Conception and design, data interpretation, drafting and writing manuscript. CU: Data analysis and interpretation, acquisition of data and illustrations. SK: Data analysis and interpretation, critical revision. MRH: Conception and design, data interpretation, critical revision. The authors read and approved the final manuscript.

Funding

No specific funding.

Availability of data and materials

Data included in manuscript. 
The datasets used and/or analyzed during the current study available from the corresponding author on reasonable request.

\section{Declarations}

\section{Ethics approval and consent to participate}

This study is a literature review. No Human Studies. No Institutional Review Board approval was needed.

\section{Consent for publication}

Not applicable.

\section{Competing interests}

None.

\section{Author details}

'Department of Pediatrics, State University of New York Downstate Medical Center, 450 Clarkson Ave., Box 49, Brooklyn, NY 11203, USA. ${ }^{2}$ School of Public Health, State University of New York Downstate Medical Center, New York, Brooklyn, USA

Received: 11 November 2020 Accepted: 8 February 2021 Published online: 17 March 2021

\section{References}

1. Credé CSF. Die Verhuetung der Augenentzundung der Neugeborenen [Prevention of inflammatory eye disease in the newborn]. Arch Gynaekol. 1881:18:367-70

2. Centers for Disease Control and Prevention: Recommendations for the Prevention and Management of Chlamydia trachomatis infections, 1993. MMWR Recomm Rep. 1993; 42(RR-12). Available at: www.cdc.gov/mmwr/ preview/mmwrhtml/00021622.html. Accessed November 4, 2019.

3. Hammerschlag MR, Cummings C, Roblin PM, Williams TH, Delke I. Efficacy of neonatal ocular prophylaxis for the prevention of chlamydial and gonococcal conjunctivitis. N Engl J Med. 1989;320(12):769-72. https://doi. org/10.1056/NEJM198903233201204.

4. Centers for Disease Control and Prevention. Sexually Transmitted Diseases Treatment Guidelines, 2015. MMWR Recomm Rep. 2015;64:1-137.

5. Banniettis N, Clement N, Hammerschlag M, Kohlhoff S. The effect of prenatal screening for Chlamydia trachomatis on chlamydial conjunctivitis in infants. Open Forum Infect Dis. 2018;5(suppl_1):S222 https://doi.org/10.1 093/ofid/ofy210.615. Accessed November 4, 2019, 608. The Effect of Prenatal Screening forChlamydia trachomatis(CT) on Chlamydial Conjunctivitis in Infants, 5, suppl 1.

6. Kreisel K, Weston E, Braxton J, Llata E, Torrone E. Keeping an eye on chlamydia and gonorrhea conjunctivitis in infants in the United States, 2010-2015. Sex Trans Dis. 2017;44(6):356-8. https://doi.org/10.1097/OLQ. 0000000000000613.

7. Hammerschlag MR, Kohlhoff S. Infections caused by Chlamydia trachomatis. In: Cherry J, Demmler-Harrison GJ, Kaplan SL, Steinbach WL, Hotez P, editors. Feigin and Cherry's textbook of pediatric infectious diseases. 7th ed. Pennsylvania: Elsevier; 2014. p. 2631-7.

8. Hammerschlag MR, Smith-Norowitz TA, Kohlhoff SA. Keeping an eye on chlamydia and gonorrhea conjunctivitis in infants in the United States, 2010-2015. Sex Trans Dis. 2017;44(9):577. https://doi.org/10.1097/OLQ. 0000000000000678 .

9. Schachter J, Grossman M, Holt J, Sweet R, Goodner E, Mills J, et al. Prospective study of chlamydial infection in neonates. Lancet. 1979;2(8139): 377-80. https://doi.org/10.1016/s0140-6736(79)90400-8.

10. Hammerschlag MR, Anderka M, Semine DZ, McComb D, McCormack W, et al. Prospective study of maternal and infantile infection with Chlamydia trachomatis. Pediatrics. 1979:64(2):142-8.

11. Chandler JW, Alexander ER, Pheiffer TA, et al. Ophthalmia neonatorum associated with maternal chlamydial infection. Trans Am Acad Ophthalmol Otolaryngol. 1977;83:302-8.

12. Hammerschlag MR, Chandler JW, Alexander ER, English M, Chiang WT, Koutsky L, Eschenbach DA, Smith JR, et al. Erythromycin ointment for ocular prophylaxis of neonatal chlamydial infection. JAMA. 1980;244(20):2291-3. https://doi.org/10.1001/jama.1980.03310200031021.
13. Centers for Disease Control and Prevention. Sexually transmitted diseases surveillance 2017. Available at: www.cdc.gov/std/stats17/. Accessed November 3, 2019.

14. WHO Guidelines Approved by the Guidelines Review Committee. WHO guidelines for the Treatment of Chlamydia trachomatis. Geneva: World Health Organization; 2016.

15. Laga A, Plummer FA, Piot P, Datta P, Namaara W, et al. Prophylaxis of gonococcal and chlamydial ophthalmia neonatorum. A comparison of silver nitrate and tetracycline. N Engl J Med. 1988;318(11):653-7. https://doi.org/1 0.1056/NEJM198803173181101.

16. Chen JY. Prophylaxis of ophthalmia neonatorum: comparison of silver nitrate, tetracycline, erythromycin and no prophylaxis. Pediatr Infect Dis J. 1992:11(12):1026-30. https://doi.org/10.1097/00006454-199211120-00007.

17. Rours GIJG, Hop WCJ, Htun Y, Radebe F, Rothberg AD, et al. Carriage of Chlamydia trachomatis during pregnancy: consequences for mother and infant. South Afr J Epidemiol. 2000;21:20-5.

18. Ali Z, Khadije D, Elahe A, Fateme N, Mohammad M, Fateme Z, Narges Z. Prophylaxis of ophthalmia neonatorum comparison of Betadine, erythromycin and no prophylaxis. J Trop Pediatr. 2007;53(6):388-92. https:// doi.org/10.1093/tropej/fmm049.

19. Matinzadeh ZK, Beiragadar F, Kavemanesh Z, Abolgasemi H, Amirsalari S. Efficacy of topical ophthalmic prophylaxis in prevention of ophthalmia neonatorum. Trop Doc. 2007;37(1):47-9. https://doi.org/10.1258/00494 7507779951880

20. Ramirez-Ortiz MA, Rodriguez-Almaraz M, Ochoa-Diazlopez H, Diaz-Prieto P, Rodriguez-Suarez RS. Randomised equivalency trial comparing $2.5 \%$ povidone-iodine drops and ophthalmic chloramphenicol for preventing neonatal conjunctivitis in a trachoma endemic area in southern Mexico. $\mathrm{Br} J$ Ophthamol. 2007;91:1430-4 Randomised equivalency trial comparing 2.5\% povidone-iodine eye drops and ophthalmic chloramphenicol for preventing neonatal conjunctivitis in a trachoma endemic area in southern Mexico, 11, DOI: https://doi.org/10.1136/bjo.2007.119867.

21. David M, Rumelt S, Weintraub Z. Efficacy comparison between povidone iodine $2.5 \%$ and tetracycline $1 \%$ in prevention of ophthalmia neonatorum. Ophthalmology. 2011;118(7):1454-8. https://doi.org/10.1016/j.ophtha.201 0.12 .003 .

22. Alexandre I, Justel M, Martinez P, Ortiz de Lejarazu R, Pastor JC. First attempt to implement ophthalmia neonatorum prophylaxis in Angola: microorganisms, efficacy and obstacles. J Ophthalmol. 2015:326526 https:// doi.org/10.1155/2015/326526. Epub 2015 Feb 16, First Attempt to Implement Ophthalmia Neonatorum Prophylaxis in Angola: Microorganisms, Efficacy, and Obstacles, 6.

23. Bell TA, Sandstrom Kl, Gravett MG, Mohan K, Kuo C-C, et al. Comparison of ophthalmic silver nitrate solution and erythromycin ointment for prevention of natally acquired Chlamydia trachomatis. Sex Transm Dis. 1987;14(4):195200. https://doi.org/10.1097/00007435-198710000-00003.

24. Lund RJ, Kibel MA, Knight GJ, Van Der Elst C. Prophylaxis against gonococcal ophthalmia neonatorum. A prospective study. S Afr Med J. 1998:72:620-2

25. Adachi K, Nielsen-Saines K, Klausner JD. Chlamydia trachomatis infection in pregnancy: the global challenge of preventing adverse pregnancy and infant outcomes in Sub-Saharan Africa and Asia. Biomed Res Int. 2016;Art. ID 9315757:21. https://doi.org/10.1155/2016/9315757, Accessed Nov 12019.

26. Moore DL, MacDonald NE. Canadian Paediatric society, infectious diseases and immunization committee. Preventing ophthalmia neonatorum. Paediatr Child Health. 2015;20(2):93-6.

27. USPSTF. Final Recommendation Statement: Ocular Prophylaxis for Gonococcal Ophthalmia Neonatorum: Prevention Medication 2014; Available from: https://www.uspreventiveservicetaskforce.org/Page/ Document/RecommendationStatementFinal/ocular-prophylaxis-forgonococcal-ophthalmia-neonatorum-preventive-medication.

28. Nathawad R, Mendez H, Ahmad A, Laungani S, Hoa BT, Garlick J, Hammerschlag MR, et al. Severe ocular reactions after neonatal prophylaxis with gentamicin ophthalmic ointment. Pediatr Infect Dis J. 2011;30(2):175-6. https://doi.org/10.1097/INF.0b013e3181f6c2e5.

29. Binenbaum G, Bruno CJ, Forbes BJ, Snyder MA, Mollen TJ, Schmidt B, Peterside I, et al. Periocular ulcerative dermatitis associated with gentamicin ointment prophylaxis in newborns. J Pediatr. 2010;156(2):320-1. https://doi. org/10.1016/j.jpeds.2009.11.060.

30. Banniettis N, Wisecup K, Byland L, Watanabe I, Hammerschlag MR, et al. Association of routine Chlamydia trachomatis screening during pregnancy 
and seroprevalence of chlamydial infection in children, 1991-2015. J Pediatr Infect Dis Soc 2020. pii: piaa002. doi: https://doi.org/10.1093/jpids/piaa002. [Epub ahead of print].

31. Kohlhoff S, Roblin PM, Clement S, Banniettis N, Hammerschlag MR. Universal prenatal screening and testing and Chlamydia trachomatis conjunctivitis in infants. Sex Transm Dis, 2020; doi: https://doi.org/10.1097/OLQ. 0000000000001344. [Epub ahead of print].

\section{Publisher's Note}

Springer Nature remains neutral with regard to jurisdictional claims in published maps and institutional affiliations.

Ready to submit your research? Choose BMC and benefit from:

- fast, convenient online submission

- thorough peer review by experienced researchers in your field

- rapid publication on acceptance

- support for research data, including large and complex data types

- gold Open Access which fosters wider collaboration and increased citations

- maximum visibility for your research: over $100 \mathrm{M}$ website views per year

At BMC, research is always in progress. 